\title{
Prevalence and burden of obstructive lung disease in the urban poor population of Ottawa, Canada: a community-based mixed-method, observational study
}

Smita Pakhale ${ }^{1,2^{*}}$ D, Saania Tariq², Nina Huynh², Sadia Jama ${ }^{2,3}$, Tina Kaur ${ }^{2}$, Catherine Charron ${ }^{1,3}$, Kelly Florence $^{4}$, Fozia Nur ${ }^{2}$, Margaret ( Ella) Bustamante-Bawagan², Ted Bignell ${ }^{4}$, Robert Boyd ${ }^{5}$, Joanne Haddad ${ }^{6}$,

Tetyana Kendzerska ${ }^{1,2}$ and Gonzalo Alvarez ${ }^{1,2}$

\begin{abstract}
Background: Globally the burden of Obstructive Lung Diseases (OLD) is growing, however its effect on urban poor populations with the high prevalence of tobacco dependence is virtually unknown. The purpose of this project is to estimate the prevalence and burden of OLD in the urban, low-income populations of Ottawa, Canada.

Methods: The study presented in this paper was part of the PROMPT (Management and Point-of-Care for Tobacco Dependence) project; a prospective cohort study in a community-based setting $(n=80)$ with meaningful Patient Engagement from design to dissemination. Spirometry data, standardized questionnaires and semi-structured interviews from PROMPT were interpreted to understand the lung function, disease burden and social determinants (respectively) in this population.
\end{abstract}

Results: The prevalence of OLD among those who completed spirometry $(N=64)$ was $45-59 \%$. Generic and disease-specific quality of life was generally poor in all PROMPT participants, even those without OLD, highlighting the higher disease burden this vulnerable population faces. Quality of life was impacted by two major themes, including i) socioeconomic status and stress and ii) social networks and related experiences of trauma.

Conclusion: The prevalence and disease burden of OLD is significantly higher in Ottawa's urban poor population than what is observed in the general Canadian population who smoke, suggesting an etiological role of the social determinants of health. This urges the need for comprehensive care programs addressing up-stream factors leading to OLDs, including poor access and utilization of preventive healthcare addressing the social determinants of health.

Trial registration: ClinicalTrails.gov - NCT03626064, Retrospective registered: August 2018.

Keywords: Urban poor, Social determinants of health, Obstructive lung disease

\footnotetext{
* Correspondence: spakhale@ohri.ca; spakhale@toh.ca

'Department of Medicine, The Ottawa Hospital, 501 Smyth Road, Ottawa,

Ontario K1H 8L6, Canada

${ }^{2}$ The Ottawa Hospital Research Institute (OHRI), Ottawa, Canada

Full list of author information is available at the end of the article
}

(c) The Author(s). 2021 Open Access This article is licensed under a Creative Commons Attribution 4.0 International License, which permits use, sharing, adaptation, distribution and reproduction in any medium or format, as long as you give appropriate credit to the original author(s) and the source, provide a link to the Creative Commons licence, and indicate if changes were made. The images or other third party material in this article are included in the article's Creative Commons licence, unless indicated otherwise in a credit line to the material. If material is not included in the article's Creative Commons licence and your intended use is not permitted by statutory regulation or exceeds the permitted use, you will need to obtain permission directly from the copyright holder. To view a copy of this licence, visit http://creativecommons.org/licenses/by/4.0/. The Creative Commons Public Domain Dedication waiver (http://creativecommons.org/publicdomain/zero/1.0/) applies to the data made available in this article, unless otherwise stated in a credit line to the data. 


\section{Background}

In the past decade, researchers have documented a growing socioeconomic inequity leading to poverty and homelessness among a group of people living in urban settings in wealthy countries (the urban poor) [1]. This characteristic low socioeconomic status (SES) in this population has been associated with co-addiction of licit and/or illicit drugs, including tobacco [2-4]. This includes tobacco cigarettes, which have led to a high prevalence of nicotine dependence and other tobaccorelated diseases in this population $[5,6]$. Previous studies working with these vulnerable groups have found that $70-96 \%$ of their cohort's smoke tobacco [6-9]. A greater mortality with a higher population attributable fraction for smoking tobacco is also seen in those with low SES compared to those with high SES $[4,10]$. Due to the higher rates of tobacco and substance use, chronic Obstructive Lung Diseases (OLDs), such as Chronic Obstructive Pulmonary Disease (COPD), asthma, and bronchiectasis, are expected to be a growing problem in the urban poor $[3,4,11]$.

While many OLDs are preventable and treatable, there is a problematic knowledge gap of undiagnosed OLDs $[12,13]$. OLDs impose a significant burden on individuals through progressive symptoms, acute pulmonary exacerbations, worsening quality of life, and premature death [12]. Social disparities such as education, occupation, racialization, and healthcare access are known to contribute to the differences in OLD-related health status in minority groups across the United States [14, 15]. However, there is minimal research that investigates the prevalence of OLDs in low-income, vulnerable populations. To our knowledge, only one small cohort study conducted in a San Francisco homeless shelter revealed that $15 \%$ of the 68 adults had spirometry-diagnosed OLD [5]. Furthermore, there is a poor understanding of the social determinants of health $(\mathrm{SDH})$ and OLD disease burden in these vulnerable groups. Hence, this paper primarily aims to estimate the prevalence and disease burden of OLDs, mainly asthma and COPD, in Ottawa's urban poor population using pre- and postbronchodilator spirometry and patient-reported health measures. Secondly, we aim to explore the SDH and experience of people living with OLD in this urban poor population to further elucidate the quality of life burden of OLDs.

\section{Methods}

Data was obtained from the Participatory Research in Ottawa: Management and Point-of-Care for Tobacco Dependence (PROMPT) Project, a prospective cohort study. PROMPT's target population included people experiencing homelessness, at-risk for homelessness (i.e., insecurely housed due to low or insecure income, and/or mental health issues, or legal challenges) or using polysubstances. The PROMPT inclusion criteria were: 1) currently living in Ottawa, Canada for at least 3 months prior to enrolment, 2) 16 years or older, 3) have used street drugs in the past year (other than recreational marijuana or alcohol), and 4) have smoked tobacco in the past 7 days. Exclusion criteria included: 1) declined consent 2) current use of in-person addictions treatment (and therefore unavailable for follow-up), 3) current or recent (past 30 days) enrollment in a smoking cessation program and 4) terminal illness, with a life expectancy of $<3$ months. During a 6-month treatment period, followup data, including patient-reported substance use and other health measures were collected. During PROMPT, pre- and post-bronchodilation spirometry was performed at baseline; analysis of which is presented here. Additionally, post-study semi-structured interviews were conducted with a subset of participants (recruited through convenience sampling) with study-spirometry diagnosed OLD. The project was approved by the Ottawa Health Science Network Research Ethics Board and written informed consent was obtained from all participants.

\section{Patient and community engagement}

The PROMPT study occurred in partnership with community (peer) researchers; people with lived experience truly representative of the target population (e.g., people who smoke, are homeless or at-risk for homelessness or use poly-substances). Peers underwent intensive training, including study protocol (consent, recruitment, and research ethics), conducting semi-structure interviews and administrating spirometry. Peers used a social-network approach to recruit participants and completed baseline enrollment, including administering informed consent, an iPad-based questionnaire, and hand-held spirometry.

All participants had access to free nicotine replacement therapy, one-on-one nurse counselling twice a week, ongoing peer support, peer-led weekly life-skills workshops, and access to a safe, non-judgmental, low-threshold community-based research space ("The Bridge" Engagement Centre) for 6 months. Peers administered monthly follow-up surveys, spirometry at the last follow-up, and a post-study semi-structed interview. Additional details on the design to dissemination Patient Engagement model, the 'Ottawa Citizen Engagement and Action Model' (OCEAM) [16] and PROMPT project details, are published elsewhere [7, 17].

\section{Data and measures}

Data on seven patient-reported measures, administered by the peers to all participants at baseline included: 1) demographic questionnaires designed with peers (including detailed smoking history, drug use, and social 
network) (see Additional File 3), 2) BOLD core questionnaire used in the CanCOLD study, 3) COPD Assessment Test (CAT), 4) EQ-5D-3L to measure quality of life, 5) Patient Health Questionnaire (PHQ-8), and 6) the Generalized Anxiety Disorder (GAD-7) questionnaire (see Additional File 2). Participants who consented and were physically able underwent pre- and postbronchodilator (before and after inhaling $200 \mu \mathrm{g}$ of salbutamol) spirometry to assess lung function. Prior to spirometry, participants completed spirometry safety questions to rule out any contraindications [18]. Peers conducted all hand-held spirometry at the Bridge, after receiving a standardized hand-held spirometry training from the study respirologist (SP). Peers were required to achieve at least 8 grade $\mathrm{A}$ or B maneuvers (programmed by the 'EasyOne' handheld diagnostic spirometer from NDD Medical Technologies) to maintain test quality and received regular feedback from the study respirologist, who was onsite 4 times per week alongside the study nurse and study coordinator. Further details on the spirometry training and administration have been previously published [17]. Lastly, we designed a post-study semi-structure interview guide in partnership with the peers, consisting of a series of open-ended questions regarding health, income, education, health services, and the surrounding physical environment. The use of openended questions allowed participants to freely share their feelings and attitudes about different aspects of their lived experience that may be relevant to the topics at hand.

\section{Interpretation of Spirometry}

To estimate predicted values of spirometry (adjusting for age, sex, height and weight) we utilized The National Health and Nutrition Examination Survey (NHANES) III formula [19]. Spirometry interpretation was according to the American Thoracic Society/European Respiratory Society (ATS/ERS) interpretative strategies [18]. Two spirometry interpretation methods labeled participants with COPD: fixed ratio (a post-bronchodilator Forced Expiratory Volume in $1 \mathrm{~s} /$ Forced Vital Capacity $\left(\mathrm{FEV}_{1} /\right.$ FVC) ratio <.70) and the Lower Limit of Normal (LLN) (a post-bronchodilator $\mathrm{FEV}_{1} / \mathrm{FVC}$ ratio $\leq \mathrm{LLN}$ ). To calculate the LLN, we used the lower 5th percentile of $\mathrm{FEV}_{1} / \mathrm{FVC}$ ratio using NHANES III reference equations [19]. Due to lack of appropriate reference data based on race, including Indigenous and East Asian origin, Caucasian reference values were only used. Participants labeled with Asthma showed significant reversibility, defined as pre-bronchodilation $\mathrm{FEV}_{1} / \mathrm{FVC}$ ratio $<.70$ or $\leq$ LLN with an improvement of $\geq 12 \%$ and $200 \mathrm{cc}$ in $\mathrm{FEV}_{1}$ or FVC post-bronchodilation.

\section{Statistical analysis}

We completed descriptive statistics to estimate baseline population characteristics. To calculate questionnaire specific score and proportions we used the scoring methods of the CAT, EQ-5D-3L, PHQ-8, and GAD-7. Lastly, we calculated confidence intervals (CI) at $95 \%$ for disease prevalence and burden.

\section{Qualitative analysis}

Anonymized interview transcripts were analysed using inductive thematic analysis with NVivo Software 12 . Codes generated by two independent coders were compared and a final list of codes and overarching themes was determined. Resulting themes were used to gain a better understanding of the population characteristics and further explain quantitative results.

\section{Results}

From March to August 2016, 2 to 4 peers recruited 80 participants from the Ottawa urban poor population, with less than $5 \%$ of potential participants contacted but not enrolled. Of the 80 participants, 67 completed spirometry at baseline, while 13 participants did not complete spirometry because of contraindications. Additionally, we removed 3 test results from the data set because of poorquality spirometry tests (i.e., over $40 \%$ decrease in postbronchodilation performance or inconsistent $\mathrm{FEV}_{1}$ and FVC outputs). Therefore, the analysis was conducted with 64 participants with complete spirometry data. Lastly, post-study interviews were completed with 11 participants who had study spirometry diagnosed OLD.

There were no significant differences in the baseline characteristics of the whole cohort compared to those who underwent spirometry (Table 1).

\section{Disease prevalence}

Approximately half of those with spirometry were considered to have OLD using the LLN (45, 95\% CI: 30 $60 \%$ ) and the fixed ratio (59, 95\% CI: 44-74\%) diagnostic method. Of those spirometry results indicating OLDs, 14-16\% indicated asthma (95\% CI:7-25\%; 95\% CI: 5$23 \%$ ) and $31-44 \%$ indicated COPD (95\% CI: $20-42 \%$; 95\% CI: 33-55\%), depending on spirometry diagnostic method. There was no significant difference between the two different spirometry diagnostic criteria $(p>0.05)$. Additionally, there was no significant difference in the pre-bronchodilator spirometry measurements $\left(\mathrm{FEV}_{1}\right.$ and FVC) between those with OLD and those without OLD. However, there was a significant difference of FEV1/ FVC ratios between those with OLD and those without OLD $(p<0.0001)$. As well, participants with significant bronchodilator response had a lower mean $\mathrm{FEV}_{1}$ in comparison to participants without an OLD (Table 2). 
Table 1 Demographic characteristics of the PROMPT cohort participants

\begin{tabular}{lll}
\hline Characteristic & Participants with spirometry $(\mathbf{N}=\mathbf{6 4})$ & All \\
\hline Sex (male) & $69 \%$ & $70 \%$ \\
Ethnicity & & \\
$\quad$ Caucasian & $78 \%$ & $78 \%$ \\
First Nations & $16 \%$ & $16 \%$ \\
Inuit & $1.5 \%$ & $1 \%$ \\
Métis & $1.5 \%$ & $1 \%$ \\
East Asian & $1 \%$ & $1 \%$ \\
Other & $2 \%$ & $3 \%$
\end{tabular}

All participants $(N=80)$

$70 \%$

First language

English

$90 \%$

$83 \%$

French

$9 \%$

$12 \%$

Other

$1 \%$

$\mathrm{N} / \mathrm{A}^{\mathrm{a}}$

Age

$16-30$

$31-40$

41-50

$42 \%$

$9 \%$

$51-65$

$31 \%$

$44 \%$

N/A

$0 \%$

$31 \%$

Education

Elementary/high school

High school graduate/GED

$28 \%$

Some college or university

College or university completed

$6 \%$

$26 \%$

None

$1.5 \%$

$5 \%$

$\mathrm{N} / \mathrm{A}^{\mathrm{a}}$

\section{Monthly Income}

$<\$ 499$

$\$ 500-\$ 999$

$33 \%$

$\$ 1000-\$ 1999$

$43 \%$

$34 \%$

\$2000-\$2999

$\mathrm{N} / \mathrm{A}^{\mathrm{a}}$

Food insecurity:

Always

Most of the time

$18 \%$

$10 \%$

$15 \%$

$25 \%$

$12 \%$

$18 \%$

$2 \%$

$\mathrm{N} / \mathrm{A}^{\mathrm{a}}$

Number of cigarettes per day:

$<15$

$53.8 \%$

$32.5 \%$

$15-25$

$34.6 \%$

$9 \%$

$8 \%$

$\%$

$\%$

$\%$

$\%$

$\%$

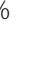

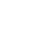


Table 1 Demographic characteristics of the PROMPT cohort participants (Continued)

\begin{tabular}{|c|c|c|}
\hline Characteristic & Participants with spirometry $(N=64)$ & All participants $(N=80)$ \\
\hline $36-40$ & $2.6 \%$ & $6.3 \%$ \\
\hline$N / A^{a}$ & $0 \%$ & $8.7 \%$ \\
\hline \multicolumn{3}{|c|}{ Total years tobacco smoking: } \\
\hline$<10$ & $31.3 \%$ & $12.5 \%$ \\
\hline $10-20$ & $11.3 \%$ & $15 \%$ \\
\hline $21-30$ & $28.7 \%$ & $33.7 \%$ \\
\hline $31-40$ & $18.7 \%$ & $25 \%$ \\
\hline $41-50$ & $7.5 \%$ & $7.5 \%$ \\
\hline $51-60$ & $2.5 \%$ & $2.5 \%$ \\
\hline$N / A^{a}$ & $0 \%$ & $3.8 \%$ \\
\hline \multicolumn{3}{|c|}{ Previous or current drug use } \\
\hline Crack & $72.7 \%$ & $66.3 \%$ \\
\hline Marijuana & $60.6 \%$ & $61.3 \%$ \\
\hline Heroine & $25.8 \%$ & $23.8 \%$ \\
\hline Fentanyl & $13.6 \%$ & $13.8 \%$ \\
\hline Oxycontin & $10.6 \%$ & $12.5 \%$ \\
\hline
\end{tabular}

${ }^{\mathrm{a}} \mathrm{N} / \mathrm{A}=$ missing or refuse to answer

${ }^{b}$ Métis - are a group of people in Canada who trace their descent to First Nations people and European settlers. They represent the majority of those identifying as Métis, though smaller communities also exist in the United States. They are recognized as one of Canada's aboriginal or indigenous people under the Constitution Act of 1982, along with First Nations and Inuit people

\section{Disease burden}

Majority of participants reported symptoms of OLD as measured by the CanCOLD questionnaire, regardless of the presence of spirometry diagnosed OLD. This included cough (64\%; 95\% CI: 51-77\%), phlegm (70\%; 95\% CI: $58-82 \%)$ shortness of breath (39\%; $95 \%$ CI:27-51\%) and, wheezing (71\%; 95\% CI: 59-83\%). A greater percentage of participants with OLD and also those with significant reversibility had more frequently reported symptoms of cough, phlegm, and shortness of breath, than those without OLD. Similarly, all participants, regardless of OLD diagnosis, reported some respiratory symptoms (especially their cough) impacting their ability to function, as measured by the CAT score (Table 3).

When participants with study-diagnosed OLD were asked to self-report chronic lung diseases, only 7 (20\%) participants reported a previous physician diagnosed chronic lung disease; indicating $80 \%$ of participants were undiagnosed. Similarly, out of the 11 participants interviewed with study-diagnosed OLD, only three reported a physician diagnosis of OLD. Participants unaware of their lung health were made aware and referred to

Table 2 Spirometry test results of the PROMPT cohort participants

\begin{tabular}{|c|c|c|c|c|c|c|}
\hline Mean (SD) & $\begin{array}{l}\text { Participants } \\
\text { with spirometry } \\
(N=64)\end{array}$ & $\begin{array}{l}\text { Participants without } \\
\text { OLD (Fixed Ratio) on } \\
\text { spirometry } \\
(N=26)\end{array}$ & $\begin{array}{l}\text { Participants } \\
\text { without OLD } \\
\text { (LLN) on } \\
\text { spirometry } \\
(N=35)\end{array}$ & $\begin{array}{l}\text { Participants with } \\
\text { OLD (Fixed Ratio) } \\
\text { on spirometry } \\
(N=38)\end{array}$ & $\begin{array}{l}\text { Participants with } \\
\text { OLD (LLN) on } \\
\text { spirometry } \\
(N=29)\end{array}$ & $\begin{array}{l}\text { Participants } \\
\text { with significant } \\
\text { reversibility on } \\
\text { spirometry } \\
(N=10)\end{array}$ \\
\hline$\overline{\mathrm{FEV}_{1}(\mathrm{~L})^{\mathrm{a}}}$ & $2.80(1.04)$ & $3.08(0.90)$ & $3.11(0.97)$ & $2.61(1.11)$ & $2.42(1.02)$ & $1.99(0.80)$ \\
\hline $\mathrm{FEV}_{1} \%$ Predicted & 76.65 (23.64) & 89.95 (19.49) & $88.52(19.41)$ & $67.55(22.04)$ & $3.84(0.73)$ & $52.91(17.48)$ \\
\hline$F V C^{b}(L)$ & $4.15(1.31)$ & $3.91(1.13)$ & $4.08(1.33)$ & $4.32(1.41)$ & $4.25(1.30)$ & $3.67(1.18)$ \\
\hline FVC \% Predicted & $76.75(23.64)$ & 91.34 (20.96) & $91.95(21.21)$ & $88.12(17.88)$ & $86.38(16.01)$ & $77.17(18.03)$ \\
\hline $\mathrm{FEV}_{1} / \mathrm{FVC}$ & $0.68(0.15)$ & $0.79(0.06)$ & $0.77(0.08)$ & $0.60(0.15)$ & $0.57(0.15)$ & $0.54(0.13)$ \\
\hline $\begin{array}{l}\text { FEV } 1 \text { Pre- \& Post-bronchodilator } \\
\text { Difference }(\mathrm{L})\end{array}$ & $-0.13(0.71)$ & $-0.13(0.58)$ & $-0.13(0.56)$ & $-0.13(0.79)$ & $-0.13(0.87)$ & $0.69(0.35)$ \\
\hline $\begin{array}{l}\mathrm{FEV}_{1} \text { Pre- \&Post-bronchodilator } \\
\text { Percent Difference }(\%)\end{array}$ & $-1.94(23.29)$ & $-3.49(17.58)$ & $-2.91(19.15)$ & $-0.88(26.69)$ & $-0.77(27.80)$ & 35.54 (12.99) \\
\hline
\end{tabular}

${ }^{\mathrm{a}} \mathrm{FEV}$, Forced Expiratory Volume in $1 \mathrm{~s}$

${ }^{\mathrm{b}}$ FVC Forced Vital Capacity 


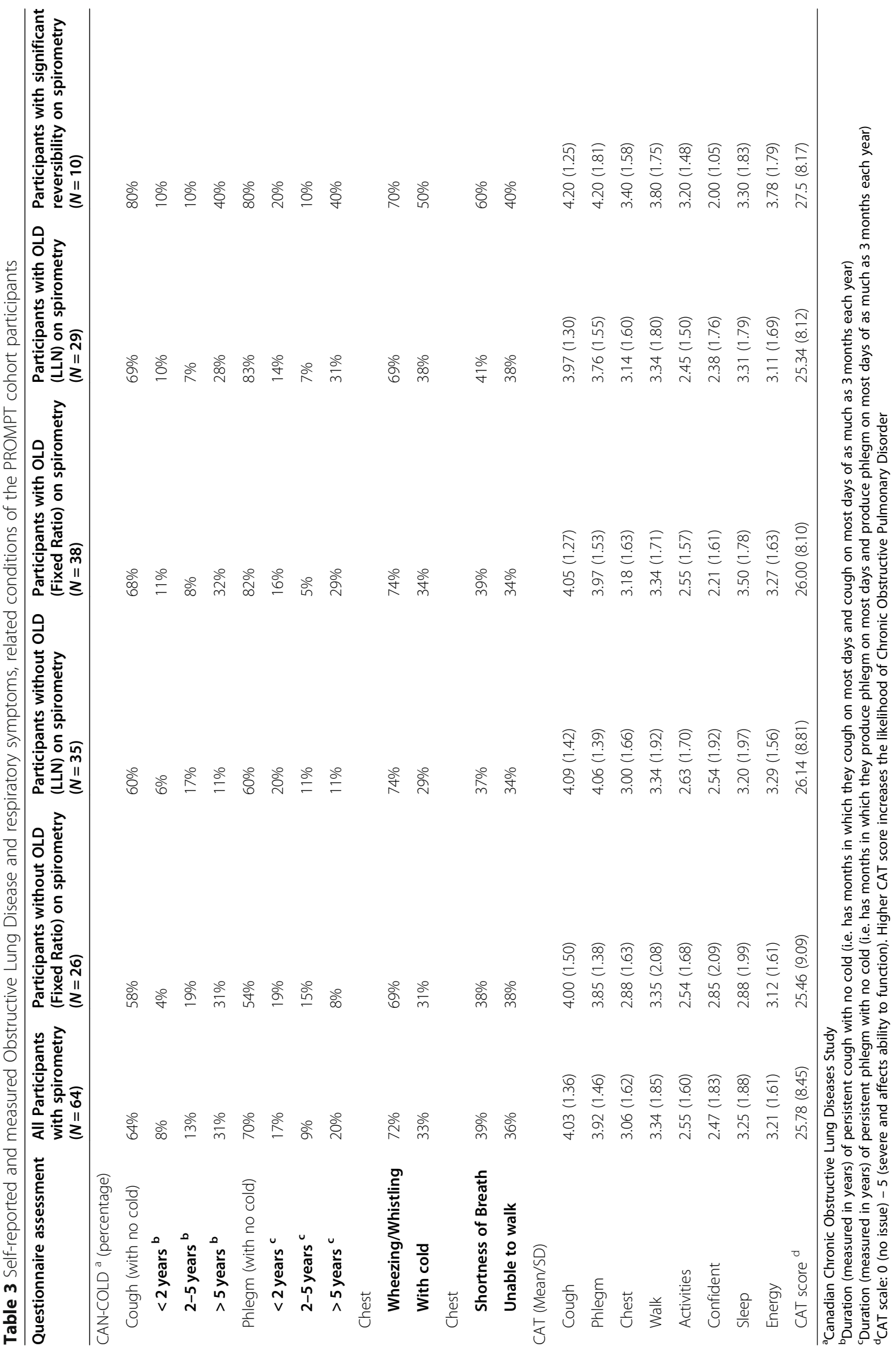


appropriate care providers. Additional to lung diseases, self-reported mental health conditions such as depression and anxiety were 35 and $29 \%$, respectively (Table 4).

Symptoms of moderate to severe anxiety (measured by GAD-7) were in $32.6 \%$ of the participants, whereas $33.8 \%$ had symptoms suggestive of moderate to severe depression (measured by PHQ-8) (Table 2). Mental health and stress appeared as a strong theme in the qualitative analysis. Participants with study diagnosed COPD often suggested they had high levels of stress due to strained access to basic resources (shelter, food, and income) and had experienced previous emotional, family, and physical trauma (Table 5).

\section{Social determinants in people with obstructive lung disease}

Overall two major themes emerged: 1) socioeconomic status and stress, and 2) social networks and related experiences of trauma. The level of income individuals had was often described as "just enough". When further explored, majority relied on social assistance payments to support their housing (market rent) and turned to informal work (day jobs cleaning, handy work, and painting) and survival work (panhandling, sex work, and drug dealing) to afford food, and (public) transportation. For example, one participant described:

Table 4 Results from the baseline GAD-7, PHQ-8 and EQ-5D-3L questionnaires of the PROMPT Cohort participants

\begin{tabular}{|c|c|c|}
\hline Questionnaire: & $\begin{array}{l}\text { Participants with } \\
\text { spirometry }(N=64)\end{array}$ & $\begin{array}{l}\text { All participants } \\
(N=80)\end{array}$ \\
\hline \multicolumn{3}{|l|}{ GAD-7 $^{b}$} \\
\hline No Anxiety ${ }^{a}$ & $48 \%$ & $33.7 \%$ \\
\hline Mild Anxiety & $19 \%$ & $30 \%$ \\
\hline Moderate Anxiety & $22 \%$ & $18.8 \%$ \\
\hline Severe anxiety & $11 \%$ & $13.8 \%$ \\
\hline Missing data & $0 \%$ & $3.7 \%$ \\
\hline \multicolumn{3}{|l|}{ PHQ-8 } \\
\hline No significant symptoms ${ }^{a}$ & $25 \%$ & $27.5 \%$ \\
\hline Mild & $39 \%$ & $37.5 \%$ \\
\hline Moderate & $21 \%$ & $20 \%$ \\
\hline Moderately severe & $13 \%$ & $12.5 \%$ \\
\hline Severe & $2 \%$ & $1.25 \%$ \\
\hline \multicolumn{3}{|l|}{ EQ-visual analogue scale } \\
\hline Mean & 61.9 & 62.2 \\
\hline Range & $3-100$ & $3-100$ \\
\hline Standard deviation & 17.4 & 17 \\
\hline
\end{tabular}

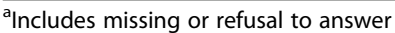

${ }^{\mathrm{b}} \mathrm{GAD}-7$ - Generalized Anxiety Disorder (7-item Questionnaire with $\geq 10$ score means a Probable Diagnosis of GAD)

${ }^{\mathrm{C}} \mathrm{PHQ}-8$ - Personal Health Questionnaire (Depression Score)
"My [income] would be right in between ... somewhat adequate ... my rent is direct, but for my monthly bills, food, transportation it's not [enough]. Some months, keeping up [with costs] is more of a struggle than others."

All individuals linked their socioeconomic situation to daily stress and reported using both negative coping strategies (substance use, isolation and avoidance) and positive coping strategies (exercise, connecting with social network and positive affirmations). The second major theme appeared through their extensive social networks and related traumatic experiences. Individuals' social network consisted of family and friends, community organizations, and people with similar SES. Physical and emotional trauma experienced by participants were often connected to their family and friends (such as the death of loved ones, sexual abuse by trusted adults) or events involving law enforcement or hospital healthcare providers:

"I've gone to the [hospital], told them about my wrist not feeling right, telling them about my elbow and arm, how badly twisted up it was by a cop. Then [they] still [did] not check [on it] or take x-rays or do anything. So, I'm kind of scared to go back to that healthcare service. If they're not going to listen to me, then why should I go. Why should I listen to them?"

Positive relationships with some family members and community health workers (nurses, workers) were also mentioned.

\section{Discussion}

OLDs place a significant burden on patients and the healthcare system in Canada. On average, conditions such as COPD and asthma attribute to a large number of emergency room visits and hospital admissions [20], with the economic burden on the Ontario provincial healthcare systems amounting to $\$ 141$ million CAN for asthma [21]. The burden of COPD exacerbations on Canada alone is estimated to be $\$ 646-736$ million CAN/ year [22]. These high costs have led to a growing effort to understand the prevalence and burden of OLD.

However, there is a lack of data on the urban poor population. In the PROMPT cohort, we observed a disproportionately high prevalence of spirometry diagnosed asthma (14-16\%) and COPD (31-44\%), regardless of spirometry interpretation strategy used. The prevalence seen in the PROMPT cohort is 2 and 3 times greater than the reported prevalence of asthma and COPD in the general Canadian population [20]. The prevalence of OLD in the PROMPT cohort is anywhere from 2 to 6 times greater than the prevalence found across cities in 
Table 5 Self-reported comorbidities of the PROMPT cohort participants

\begin{tabular}{|c|c|c|c|c|c|c|}
\hline Disease & $\begin{array}{l}\text { All participants with } \\
\text { spirometry } \\
(N=64)\end{array}$ & $\begin{array}{l}\text { Participants without } \\
\text { OLD (Fixed Ratio) } \\
\text { on spirometry } \\
(N=26)\end{array}$ & $\begin{array}{l}\text { Participants } \\
\text { without OLD (LLN) } \\
\text { on spirometry } \\
(N=35)\end{array}$ & $\begin{array}{l}\text { Participants with } \\
\text { OLD (Fixed Ratio) } \\
\text { on spirometry } \\
(N=38)\end{array}$ & $\begin{array}{l}\text { Participants with } \\
\text { OLD (LLN) on } \\
\text { spirometry }(N=29)\end{array}$ & $\begin{array}{l}\text { Participants with } \\
\text { BD response on } \\
\text { spirometry } \\
(N=10)\end{array}$ \\
\hline Lung Disease $^{a}$ & $21.88 \%$ & $26.92 \%$ & $22.86 \%$ & $18.42 \%$ & $20.69 \%$ & $20 \%$ \\
\hline Heart Disease & $9.38 \%$ & $11.54 \%$ & $11.43 \%$ & $7.89 \%$ & $6.90 \%$ & $0 \%$ \\
\hline Hypertension & $4.69 \%$ & $3.85 \%$ & $5.71 \%$ & $5.26 \%$ & $3.45 \%$ & $0 \%$ \\
\hline Diabetes & $9.38 \%$ & $11.53 \%$ & $8.57 \%$ & $7.89 \%$ & $10.34 \%$ & $20 \%$ \\
\hline Stroke & $4.69 \%$ & $3.85 \%$ & $2.86 \%$ & $5.26 \%$ & $6.90 \%$ & $0 \%$ \\
\hline Cancer & $4.69 \%$ & $3.85 \%$ & $2.86 \%$ & $5.26 \%$ & $6.90 \%$ & $0 \%$ \\
\hline Schizophrenia & $4.69 \%$ & $3.85 \%$ & $5.71 \%$ & $5.26 \%$ & $3.45 \%$ & $0 \%$ \\
\hline Depression & $37.5 \%$ & $42.31 \%$ & $34.29 \%$ & $34.21 \%$ & $41.38 \%$ & $30 \%$ \\
\hline Anxiety Disorder & $29.7 \%$ & $30.77 \%$ & $25.71 \%$ & $28.95 \%$ & $34.48 \%$ & $10 \%$ \\
\hline $\begin{array}{l}\text { Bipolar } \\
\text { Disorder }\end{array}$ & $9.38 \%$ & $11.54 \%$ & $8.57 \%$ & $7.89 \%$ & $10.34 \%$ & $0 \%$ \\
\hline Seizures & $6.25 \%$ & $0 \%$ & $0 \%$ & $10.53 \%$ & $13.79 \%$ & $0 \%$ \\
\hline
\end{tabular}

${ }^{a}$ (Asthma, Cancer, Emphysema, COPD)

Australia, Norway, Germany, United Kingdom, USA and the Netherlands [23]. Similarly, the estimated prevalence of spirometry diagnosed OLD seen in the PROMPT cohort is approximately 2 to 3 times greater than the estimated prevalence seen in a 2004 study with participants experiencing homelessness [5] and a 2011 study with urban participants using drugs [24], both in the United States.

The observed differences in these studies and our results may potentially be attributed to the participant's tobacco smoking status and severity. All participants in the PROMPT study were currently smoking cigarettes with the majority of participants having a history of greater than 20 pack-years (51\%) and smoking for more than 21 years $(57 \%)$. In both studies conducted in the US, their estimated prevalence's were based on cohorts where 68 and $88 \%$ of participants self-reported as 'current smokers'. It is possible the prevalence of OLDs in the PROMPT cohort is much greater than what is seen in the general and related populations due to the rate and severity of tobacco smoking.

Despite the common suggestion that smoking is the primary cause behind observed disparities $[3,4,11]$, the stark difference continues to exist when comparing the urban poor population who smoke to the general Canadian population who smoke. When comparing the PROMPT cohort to the CanCOLD study [25, 26] (capturing the general Canadian population with COPD and who smoke), the urban poor represented by the PROMPT cohort were much worse off (see Additional File 1); including a significantly higher prevalence of spirometry-diagnosed COPD in the urban poor population who smoke $(31-44 \%)$ than the general Canadian population who smoke $(11-17 \%)[25,26]$. Poor quality spirometry may contribute to the high prevalence of OLD in this study, however efforts were made to improve spirometry quality, including six-day standardized training, with consistent quality performance evaluations [17]. More importantly, it is difficult to deny symptoms such as cough, phlegm, shortness of breath, and wheezing. Disease burden, including cough, phlegm and wheezing, was 2-3 times higher in the PROMPT group in comparison to the CanCOLD cohort that smokes (see Additional File 1). The mean CAT score, measuring COPD burden on everyday life, is almost triple in PROMPT participants (25.78) than in the CanCOLD participants (7.8), indicating PROMPT participants are highly symptomatic (total score $\geq 10$ points) and experience greater disease burden [27]. In addition to OLD specific burden, majority of participants face comorbidities, such as mild to severe anxiety and depression, indicated by GAD-7 and PHQ-8 scores respectively.

The disproportionately high disease prevalence and co-morbidities were expected to contribute to the participant's perception of their health and everyday experience. Yet in the semi-structured interviews, the disease specific burden and management of the disease was not central to the participant's perceived health and day-today wellbeing. When asked about their health, participants with OLD focused on social determinants (such as income, trauma, social networks, education, Substance Use Disorder, mental health challenges, and food insecurity) rather than the management or symptoms related to their OLD. This is not surprising, as literature has shown SES to be a strong contributor to the severity and prevalence of OLD, rivaling the contribution of smoking [28-30]. However, these results differ from other qualitative studies looking at the lived experience of people 
with OLD, which highlight disease specific burden and management [31].

One reason that may explain why OLD specific burden was not highlighted in the post-study interviews was the alarming rates of undiagnosed OLD. Approximately 80\% of participants in PROMPT that were diagnosed with an OLD (45-59\%) reported no physician-diagnosed lung related disease, suggesting they are unaware of having an OLD. This is 4 times greater than the estimated rate of undiagnosed COPD and asthma in the general population in Canada [13]. Out of the 11 participants interviewed, 3 recognized OLD as a chronic disease they have. A similar study focusing on a US urban population that uses drugs found that $50 \%$ of their population were living with unrecognized OLD [24]. Often times, vulnerable groups have poor access to healthcare, are underdiagnosed and are undertreated, all translating to poorer health and poorer quality of life [32, 33]. However, much like SES and the other SDH, inequitable access to healthcare services are the result of structural and systematic inequities such as discrimination and stigma [34]. Together, these factors have serious implications on disease prevalence, burden, and overall quality of life.

Overall, these results suggest the presence of deep social inequities that create complex situations for people from the urban poor population living with an OLD. Addressing the $\mathrm{SDH}$, in addition to standard treatments such as pharmacotherapy or physiotherapy, should be strongly considered by policy makers, researchers, and health care professionals when designing interventions to improve the quality of life of people in the urban poor population with OLDs. Currently, the Canadian Government's action plan includes framework development and program funding [35]. While the framework recognizes the role of SDHs, the majority of their programing focuses on curbing tobacco smoking [36] and fails to recognize upstream factors we identified (such as food insecurity, trauma, housing issues and unreliable income) that dominate the day to day life of people with OLDs. One potential approach to address these components is Community-Based Participatory Action Research (CBPAR), as used in the PROMPT project [16, 37]. CBPAR engages participants as equal decisionmakers and builds trust, producing inclusive research as recommended in the American Thoracic Society/National Heart, Lung, and Blood Institute Workshop Report [15]. Future studies are encouraged to explore the effectiveness of interventions that use these communitybased approaches to combat social disparities evident in OLD prevalence.

\section{Limitations}

A major limitation in this study is being a single center with a small sample size. Nonetheless, it is the first study demonstrating the OLD prevalence and disease burden measured by spirometry in the urban poor population. Furthermore, a selection bias could be present in recruitment as peer researchers utilized their social networks. For these reasons, our results should be generalized to populations in other settings across Canada with hesitancy. However, the demographic variables are similar to other cohort projects in the same population in North America, suggesting this cohort to be a representative sample of this population [38-41]. Additionally, our conscientious effort to utilize a social-network recruitment method in a community-based patient engagement approach helped to minimize mistrust, accessibility, and other common barriers faced by vulnerable populations when participating in research $[7,42]$.

The differences highlighted between the urban poor population and other populations (higher SES) may be considered to be obvious to some. However, this can lead to the growing exclusion of this population from potential research-based solutions for complex social and health related issues [43]. Lastly, we labelled participants with OLDs, including COPD and asthma only; the incidence of others, including bronchiectasis and chronic bronchitis, were not captured. Also, we did not capture the incidence of restrictive lung conditions, that may have an impact on the respiratory disease prevalence and burden in the urban poor population. Future studies are recommended to use respiratory, physiological, and radiological assessments, to help determine the complete picture of lung diseases in this underserved population.

\section{Conclusion}

The most-vulnerable, low-income population of Ottawa, Canada is estimated to disproportionately experience a high prevalence and disease burden of OLD while facing challenging SDH. These findings suggest a significant health and social inequity, uncovering issues of poor social determinants of health and access to healthcare in Canada. Overall, this prompts the need for further research investigating the depth of these issues, and a new approach for clinical-based research, which integrate comprehensive, community-based programs for the most vulnerable populations.

\section{Supplementary Information}

The online version contains supplementary material available at https://doi. org/10.1186/s12889-021-10209-w.

\footnotetext{
Additional file 1. General Population vs Urban Poor Population, PROMPT and CanCOLD: Shows comparison between PROMPT population and General Canadian Population, including discussion and 2 tables.

Additional file 2. Measures: Describes details on 3 measures used in study, including description, scoring and interpretation.

Additional file 3. Demographic Questionnaire: Co-designed with community peer researchers for the PROMPT project.
} 


\section{Abbreviations}

COPD: Chronic obstructive lung disease; OLD: Obstructive lung disease; LLN: Lower limit than normal; PROMPT: Participatory Research in Ottawa: Management and Point-of-Care for Tobacco Dependence; SES: Socioeconomic status; SDH: Social determinants of health

\section{Acknowledgements}

The authors are indebted to our PROMPT community researchers, without their trust in the research team and dedication towards a harm reduction approach, this project would not be possible. Participants demonstrated resilience throughout the project, and we are very grateful for their inner strength. The authors also wish to thank local allies: Oasis, Sandy Hill Community Health Centre (CHC), Somerset West $\mathrm{CHC}$, without their support it would not have been possible to implement the project. The Community Advisory Committee at The Bridge, comprised of Tara, Rick, TB and Petrina (PROMPT participants) and KF (a PROMPT peer researcher), RB (Oasis, Sandy Hill CHC), S. Willmott (Somerset CHC), JH (CMHA), K. McNaughton (Ottawa Inner City Health Inc.), and S. Pakhale (The Bridge lead scientist) meet monthly at The Bridge and guide the mission and vision of the space along with overseeing the smooth functioning of projects. The authors are indebted to the vision, dedication and passion of The Bridge CAC. The authors are thankful to the Ottawa Hospital, especially Dr. Jack Kitts, Dr. Jim Worthington, Dr. Mike Tierney, Dr. Bill Cameron, Dr. lan Graham, Dr. Antoine Hakim and the administrative staff for their support. The authors thank the EuroQol questionnaire team (EQ-5D-3L) for allowing them to use the questionnaire pro-bono for this project. Last but not least, the authors are grateful to all the reviewers of this manuscript, their feedback was immensely helpful and undoubtedly improved the quality of our manuscript significantly.

\section{Authors' contributions}

SP had full access to all of the data in the study and takes responsibility for the integrity of the data and the accuracy of the data analysis. SP contributed to the conception and design of the study. SP, KF, TB, TK, CC, SJ, $\mathrm{JH}, \mathrm{MB}, \mathrm{ST}$ and FN made substantial contributions to the acquisition of the data, data entry, or data analysis and data interpretation. SP, TF, CC, TB, TK, $S J, R B, J H, M B, S T, F N, N H, G A$ and TK were all involved in the drafting of the manuscript or the revisions made to the manuscript. All authors have given final approval of the version of the manuscript submitted for publication and agree to be accountable for all aspects of the work.

\section{Funding}

This work was supported by the Champlain Local Health Integration Network; Department of Medicine and the Divisions of Respirology and Cardiology at the Ottawa Hospital, Ottawa, Canada (Grant number: NA). All funders had no role in the design on the study, data collection, data analysis, interpretation of data and in writing the manuscript.

\section{Availability of data and materials}

Parent study (Management and Point-of-Care of Tobacco: A CommunityBased Participatory Action Research Project, PROMPT) is available here (https://doi.org/10.1136/bmjopen-2017-018416). The Clinical Trails registry for the PROMPT study can be found here (ClinicalTrails.gov Identifier: NCT03626064). All available data can be obtained by contacting the corresponding author.

\section{Ethics approval and consent to participate}

The project was approved by the Ottawa Health Science Network Research Ethics Board and written informed consent was obtained from all participants.

\section{Consent for publication}

Not Applicable

\section{Competing interests}

The authors report no conflict of interest.

\section{Author details}

'Department of Medicine, The Ottawa Hospital, 501 Smyth Road, Ottawa, Ontario K1H 8L6, Canada. ${ }^{2}$ The Ottawa Hospital Research Institute (OHRI), Ottawa, Canada. ${ }^{3}$ University of Ottawa, Ottawa, Canada. ${ }^{4}$ Community (peer) Researcher, The Bridge Engagement Centre, Ottawa, Canada. ${ }^{5}$ Oasis, Sandy
Hill Community Health Centre, Ottawa, Canada. ${ }^{6}$ Canadian Mental Health Association, The Ottawa Branch, Ottawa, Canada.

Received: 6 September 2020 Accepted: 10 January 2021

Published online: 21 January 2021

\section{References}

1. Hajnal ZL. The nature of concentrated urban poverty in Canada and the United States. Can J Sociol / Cah Can Sociol. 1995:20(4):497.

2. Burki TK. Homelessness and respiratory disease. Lancet Respir Med. 2017; 1(10):767-8.

3. Di Cesare M, Khang YH, Asaria P, Blakely T, Cowan MJ, Farzadfar F, et al. Inequalities in non-communicable diseases and effective responses. Lancet. 2017;381(9866):585-97.

4. Stringhini S, Carmeli C, Jokela M, Avendao M, Muennig P, Guida F, et al. Socioeconomic status and the $25 \times 25$ risk factors as determinants of premature mortality: a multicohort study and meta-analysis of 1.7 million men and women. Lancet. 2017.

5. Snyder LD, Eisner MD. OBstructive lung disease among the urban homeless*. Chest. 2004;125(5):1719-25.

6. Tsai J, Rosenheck RA. Smoking among chronically homeless adults: prevalence and correlates. Psychiatr Serv. 2012;63(6):569-76.

7. Pakhale S, Kaur T, Rose T, Florence K, LeBlanc S, Muckle W, et al. The PROMPT study: participatory research in Ottawa: management and point-ofcare of tobacco-a community-based participatory action research project. BMJ Open. 2017.

8. Vijayaraghavan M, Tieu L, Ponath C, Guzman D, Kushel M. Tobacco cessation behaviors among older homeless adults: results from the HOPE HOME study. Nicotine Tob Res. 2016;18(8):1733-9.

9. Vijayaraghavan M, Pierce JP. Interest in smoking cessation related to a smoke-free policy among homeless adults. J Community Health. 2015;40(4): 686-91.

10. Chetty $\mathrm{R}$, Stepner $\mathrm{M}$, Abraham $\mathrm{S}$. The association between income and life expectancy in the United States, 2001-2014. JAMA. 2016;315(16):1750-66.

11. Leone FT, Carlsen K-H, Chooljian D, Alexander LEC, Detterbeck FC, Eakin MN, et al. Recommendations for the appropriate structure, communication, and investigation of tobacco harm reduction claims an official American thoracic society policy statement. Am J Respir Crit Care Med. 2018;198(8).

12. Vogelmeier CF, Criner GJ, Martinez FJ, Anzueto A, Barnes PJ, Bourbeau J, et al. Global strategy for the diagnosis, management and prevention of chronic obstructive lung disease 2017 report. Respirology. 2017;22(3):575-601.

13. Preteroti $M$, Whitmore $G A$, Vandemheen $\mathrm{KL}$, FitzGerald JM, Lemière $C$, Boulet LP, et al. Population-based case-finding to identify subjects with undiagnosed asthma or COPD. Eur Respir J. 2020;55(6).

14. Martinez CH, Mannino DM, Curtis JL, Han MK, Diaz AA. Socioeconomic characteristics are major contributors to ethnic differences in health status in obstructive lung disease: an analysis of the National Health and Nutrition Examination Survey 2007-2010. CHEST J. 2015;148(1):151-8.

15. Celedon JC, Burchard EG, Schraufnagel D, Castillo-Salgado C, Schenker M, Balmes J, et al. An American Thoracic Society/National Heart, Lung, and Blood Institute Workshop Report: addressing respiratory health equality in the United States. Ann Am Thorac Soc. 2017;14(5):814-26.

16. Pakhale S, Kaur T, Florence K, Rose T, Boyd R, Haddad J, et al. The Ottawa Citizen Engagement and Action Model (OCEAM): a citizen engagement strategy operationalized through the Participatory Research in Ottawa, Management and Point-of-care of Tobacco (PROMPT) study. Res Involv Engagem. 2016;2(1):1-18.

17. Charron CB, Hudani A, Kaur T, Rose T, Florence K, Jama S, et al. Assessing community (peer) researcher's experiences with conducting spirometry and being engaged in the 'Participatory Research in Ottawa: Management and Point-of-care for Tobacco-dependence'(PROMPT) project. Res Involv Engagem. 2018;4(1):43

18. Pellegrino R, Viegi G, Brusasco V, Crapo RO, Burgos F, Casaburi R, et al. SERl ES "'ATS/ERS TASK FORCE: STANDARDISATION OF LUNG FUNCTION TEST ING'" Number 5 in this Series Interpretative strategies for lung function tests. Brusasco V, Crapo R, Viegi G, editors. Eur Respir J. 2005;26:948-68.

19. Hankinson JL, Odencrantz JR, Fedan KB. Spirometric reference values from a sample of the general U.S. population. Am J Respir Crit Care Med. 1999;159.

20. REPORT FROM THE CANADIAN CHRONIC DISEASE SURVEILLANCE SYSTEM. Asthma and chronic obstructive pulmonary disease (COPD) in Canada, 2018. Ottawa; 2018. 
21. Ismaila AS, Sayani AP, Marin M, Su Z. Clinical, economic, and humanistic burden of asthma in Canada: a systematic review. BMC Pulm Med. 2013;13(1):70.

22. Mittmann N, Kuramoto L, Seung SJ, Haddon JM, Bradley-Kennedy C, FitzGerald JM. The cost of moderate and severe COPD exacerbations to the Canadian healthcare system. Respir Med. 2008;102(3):413-21.

23. Burney P, Jithoo A, Kato B, Janson C, Mannino D, Nizankowska-Mogilnicka E, et al. Chronic obstructive pulmonary disease mortality and prevalence: the associations with smoking and poverty-a bold analysis. Thorax. 2014;69(5): 465-73.

24. Drummond MB, Kirk GD, Astemborski J, McCormack MC, Marshall MM, Mehta $\mathrm{SH}$, et al. Prevalence and risk factors for unrecognized obstructive lung disease among urban drug users. Int J COPD. 2011;6(1):89-95.

25. Chronic Obstructive Pulmonary Disease (COPD) in Canada. Government of Canada, Data Blog. 2018.

26. van Dijk W, Tan W, Li P, Guo B, Li S, Benedetti A, et al. Clinical relevance of fixed ratio vs lower limit of normal of FEV (1)/FVC in COPD: patient-reported outcomes from the CanCOLD cohort. Ann Fam Med. 2015;13(1):41-8.

27. Houben-Wilke $S$, Janssen DJA, Franssen FME, Vanfleteren LEGW, Wouters EFM, Spruit MA. Contribution of individual COPD assessment test (CAT) items to CAT total score and effects of pulmonary rehabilitation on CAT scores. Health Qual Life Outcomes. 2018;16(1):205.

28. Atis Nayci S, Ozgur E, Ozge C. Socioeconomic status shaping GOLD A-D classification in patients with chronic obstructive pulmonary disease. In: European Respiratory Journal: European Respiratory Society (ERS); 2016. p. PA3683.

29. Eisner MD, Blanc PD, Omachi TA, Yelin EH, Sidney S, Katz PP, et al. Socioeconomic status, race and COPD health outcomes. J Epidemiol Community Health. 2011;65(1):26-34.

30. Prescott E, Vestbo J. Socioeconomic status and chronic obstructive pulmonary disease. Thorax. 1999;54:737-41 BMJ Publishing Group.

31. Disler R, Green A, Luckett T, Newton P, Inglis S, Currow D, et al. Experience of advanced chronic obstructive pulmonary disease: metasynthesis of qualitative research. J Pain Symptom Manag. 2014;48(6):1182-99.

32. Hwang SW, Ueng JJM, Chiu S, Kiss A, Tolomiczenko G, Cowan L, et al. Universal health insurance and health care access for homeless persons. Am J Public Health. 2010;100(8):1454-61.

33. Baggett TP, O'Connell JJ, Singer DE, Rigotti NA. The unmet health care needs of homeless adults: a national study. Am J Public Health. 2010;100(7):1326-33.

34. National Academies of Sciences $\mathrm{E}$ and $\mathrm{M}$, Division $\mathrm{H}$ and $\mathrm{M}$, Practice $\mathrm{B}$ on PH and PH, States C on C-BS to PHE in the U, Baciu A, Negussie Y, et al. The Root Causes of Health Inequity. 2017.

35. About the Framework | National Lung Health Framework. Available from: https:/ www.lunghealthframework.ca/about-framework. Accessed 22 Dec 2020.

36. How the National Lung Health Framework's Database Can Help You. Available from: www.lunghealthframework.ca. Accessed 22 Dec 2020.

37. Harris DA, Pensa MA, Redlich CA, Pisani MA, Rosenthal MS. Communitybased participatory research is needed to address pulmonary health disparities. Ann Am Thorac Soc. 2016;13(8):1231-8.

38. Hwang SW, Aubry T, Palepu A, Farrell S, Nisenbaum R, Hubley AM, et al. The health and housing in transition study: a longitudinal study of the health of homeless and vulnerably housed adults in three Canadian cities. Int J Public Health. 2011;56(6):609-23.

39. Vijayaraghavan M, Jacobs EA, Seligman H, Fernandez A. The association between housing instability, food insecurity, and diabetes self-efficacy in low-income adults. J Health Care Poor Underserved. 2011;22(4):1279-91.

40. Wiebel WW, Jimenez A, Johnson W, Ouellet L, Jovanovic B, Lampinen T, et al. Risk behavior and HIV seroincidence among out-of-treatment injection drug users: a four-year prospective study. JAIDS J Acquir Immune Defic Syndr. 1996;12(3):282-9.

41. Argintaru N, Chambers C, Gogosis E, Farrell S, Palepu A, Klodawsky F, et al. A cross-sectional observational study of unmet health needs among homeless and vulnerably housed adults in three Canadian cities. BMC Public Health. 2013;13:577.

42. George S, Duran N, Norris K. A systematic review of barriers and facilitators to minority research participation among African Americans, Latinos, Asian Americans, and Pacific Islanders. Am J Public Health. 2014;104(2):e16-31.

43. Anderson I, Filipovič Hrast M, Finnerty J. Researching homelessness: Challenging exclusion? Vol. 4, Social Inclusion: Cogitatio Press; 2016. p. 1-4.

\section{Publisher's Note}

Springer Nature remains neutral with regard to jurisdictional claims in published maps and institutional affiliations.

\section{Ready to submit your research? Choose BMC and benefit from:}

- fast, convenient online submission

- thorough peer review by experienced researchers in your field

- rapid publication on acceptance

- support for research data, including large and complex data types

- gold Open Access which fosters wider collaboration and increased citations

- maximum visibility for your research: over $100 \mathrm{M}$ website views per year

At BMC, research is always in progress.

Learn more biomedcentral.com/submissions 